UDC 631.45

(C) 2016

\title{
Agrology and farming agriculture in the countries with arid climate
}

V. Medvedev,

Academician of the National Academy of Sciences of Ukraine, Doctor of Biological Sciences

National Scientific Center «Institute of Soil Science and Agrochemistry named after O.N. Sokolovsky»

The purpose. To discuss state of researches in agrology in the countries of Northern Africa, Near and Middle East which are important for support of farming agriculture in droughty conditions. Methods. Analysis of the information. Results. A lot of research and development and educational establishments operate in countries with an arid climate, especially in Turkey and Iran. Various researches at high methodical level, directed, primarily, on acclimatization of farming agriculture to unfavorable climatic conditions, overcoming of desertification, salification and degradation of soils are carried out. Conclusions. Experience of support of pasture husbandry, as well as study and cultivation of soils of pastures, eroded soils, and various methods of phyto-remediation, irrigation and use of artificial soil are worthy to investigate in Ukraine, considering possible climate fluctuations, especially in drysteppe zone.

Key words: agrology, farming agriculture, droughty conditions.

Agriculture in the countries of North Africa, the Near and the Middle East is carried out under very difficult climatic conditions. The annual rainfall is less than $300 \mathrm{~mm}$, the air temperature during the growing of field crops - above $30-35^{\circ} \mathrm{C}$, unfavorable soil conditions. For example, in Turkey, almost $80 \%$ of the territory is eroded, and $22 \%$ - in a very strong degree [1], widespread erosion in Iran, Lebanon and Algeria. About $80 \%$ of Iran's territory is desert or deserted land [2].

Soils are often subjected to different types of salinity (sodium or gypsum). In Algeria, a significant proportion of irrigated land is re-salinated. In addition, in this country, due to the extremely intensive exploitation of water resources and almost lack of measures to protect them, there is a shortage of them and a decrease in quality through pollution [3]. In Turkey, especially in the western coastal regions, as in European countries, some concern is caused by uncontrolled urbanization and the reduction of land suitable for agricultural use, which has intensified in the last 25 years. At the same time there is a variety of studies on the impact of pollution and sealing on the soil.

Desertification is widespread; it is manifested in xerophilization of vegetation and physical degradation of soils (non-structural, fusibility, peal formation). Soil protection measures are used not enough. Thus, in Turkey over the past 50 years, anti-erosion measures have been launched only on $10 \%$ of agricultural land [1]. Such unsatisfactory state of overcoming erosion is noted in the modern developed country, despite the existence of large-scale projects within the Ministry of Forestry and Water Affairs. In Turkey and Iran, considerable efforts are made to overcome desertification and land degradation.

Tenser situation is with wind erosion. It is believed that in Turkey about 0.5 million hectares is under its strong influence. Only in recent years, at one of the experimental stations in the zone of dust storm detection, where the wind speed in March reached $25 \mathrm{~m} / \mathrm{s}$, field experiments were conducted to determine soil losses using special equipment [4].

Experiments were conducted on arable areas and pastures against a background of a wide range of wind speeds. The greatest loss of soil was found on arable land $-0.191 \mathrm{~kg} / \mathrm{m} / \mathrm{h}$, the lowest - in the pastures $-0.077 \mathrm{~kg} / \mathrm{m} / \mathrm{year}$. The study noted a tight relationship of soil losses with its granulometric composition, aggregate size, soil moisture, surface roughness, vegetation cover and wind speed. It is established that the climatic features of the Persian Gulf and the Red Sea are reflected in the phenomena of soil deflation. The forecast of the distribution of regions with wind erosion in the near and distant times is worked out. 
Researchers from the Tunisian Institute of Arid Regions, together with researchers at the University of Leeds, assessed the degradation of soils in North Africa (especially through wind erosion) using the PESERA model [5]. The main factors - land use, soil cover, climatic parameters, topography of the area are taken into account. It was concluded that deflation is the main problem of soil degradation in this region.

Wind erosion and dust storms are a common occurrence for deserted soils, but they are difficult to predict because detailed climate control is required over a long period of time. This analysis was carried out by a team of researchers from the Tehran Agricultural College [6]. The spatial-temporal distribution of dust storms at 27 meteorological stations was studied with the definition of the main weather indicators and the state of the soil surface. The regions of the most likely manifestation of the storms (border with the Iraq region) are found, their duration (from 1.8 to 102 days per year), climatic conditions that cause them (temperature, precipitation, humidity, wind speed, etc.). The spatial and temporal parameters of dust storms were estimated using geostatistical and geoinformation methods.

H.R. Matinfar and others [7] from the Lorestan University of Iran used successfully satellite information to monitor degraded soils on the Central Iranian Plateau. It turned out that according to remote sensing it is possible to diagnose pasture with overpopulation, deflationary degraded soils and areas with foci of water erosion.

I. Amiri and others [8] from Iran Zabol University investigated the impact of various obstacles on the way to the wind flow. It turned out that even the shafts of the simplified design are no less effective to reduce erosion than palm bands.

An extremely important problem in North Africa, especially in Algeria, is the consolidation of sand dunes from dispersal. Promising ones are considered a variety of biological methods, in particular, planting adapted to lack of plant moisture and maintenance of grass cover.

An experiment [9] conducted in Northern Iran showed that the growth during 20-40 years of tea plantation in place of the forest, led to significant depletion of soil on total nitrogen, available forms of phosphorus and potassium, exchange cations $\mathrm{Ca}$ and $\mathrm{Mg}$, decrease in $\mathrm{pH}$ and Organic carbon content.

I. Ortas i S. Kapur, leading soil scientists in Turkey, along with the famous American scientist R. Lal [10] presented a fundamental article about the soils of the Middle East after the so-called green revolution of the 1960s. The Green Revolution (fertilizers, pesticides, irrigation, improved varieties and methods of cultivating soils) has greatly improved the food supply of the region and reduced the fertility of soils. The main reason for this is the decrease in the content of organic matter in the soil and the deterioration of the structure. Unfortunately, the "Green Revolution" at the same time led to the deterioration of the environment state. There was the wrong management and widespread burning stubble. The report presents the results of several long-term field experiments in which the issue of the sequestration of soil carbon (reducing its atmospheric losses) was successfully solved.

Much attention is paid to studying the state of the soil cover of pastures under different conditions of their containment. In work by M. Nael et al. [11] from Central Iran, the physical and chemical properties of the soil of unused pasture and pastures with different state of overpopulation are estimated. Particularly noticeable it was the decrease in the deteriorated pasture content of organic carbon, the activity of microflora (especially phosphatase), hydraulic conductivity. It was found out that the temporary renaturalization of pastures grazed by sheep restores organic matter and structural state of the soil, almost eliminates the crust, and improves the condition of the surface and other properties. During 5 years the state of the intensively used pasture is approaching its unused analogue.

Approximately the same conclusions about the impact of renaturation on the state of deteriorated pastures have been made in other works by scientists from Algeria and Sicily (Italy), but the term of restoration of the properties of soils was considerably longer - 30-50 years.

It should be noted that the issue of renaturalization of pastures, degraded as a result of overexposure, is very popular. Sealing of the surface layer of the soil under the influence of overexposure reached 
ultrahigh values. So, in the work by I. Jafaria et al. [12] the density of the structure has increased from $1.54 \mathrm{~g} / \mathrm{cm}^{3}$ on cultivated pasture to $1.73 \mathrm{~g} / \mathrm{cm}^{3}$ on the bred sheep grazing. Simultaneous porosity has reached critical values.

In western Azerbaijan (the province of Iran) there were investigated the areas that previously were under the forest, they became pastures, gardens and arable land. The density of the structure in these variants in the upper layer reached, respectively, $1.24 ; 1.32$ and $1.29 \mathrm{~g} / \mathrm{cm}^{3}$ for density in the forest of $0.99 \mathrm{~g} / \mathrm{cm}^{3}$ [13].

Increased forest cover is considered as an important trend in overcoming desertification. In Central Iran, dominated by deserts and deserted territories, the flooding with special vegetation types adapted to the lack of moisture led to radical changes in the area - increased biodiversity of the animal world, changes in the climate and in general to improve the aesthetic appeal of the landscape [2].

In Morocco and southern Italy, pine trees are explored to restore forestness on deserted lands, and canola and mustard are sown in Algeria and Iran on cut pastures. In Central Iran, arable land is subject to minimal and conservative methods of cultivation instead of plowing. No positive effect was observed from zero cultivation on irrigated lands, but conservative tillage on the background of irrigation contributed to the irrigation of soils in the root-bearing layer.

In Central Iran, on heavy clay soils with ultra-high parameters of hardness a positive effect was achieved from the use of organic wastes, especially wastes from nut and tea plantations 8 months after they were taken, eventually it intensified.

A series of papers on the effect of salinization on germination of seeds deserves attention. So, in the work by S. Hassan et al. from the Iranian University of Natural Resources in Ahwaz, the effect of 5 levels of artificial salinity on germination of various varieties of canola was investigated. Concomitant observations in this study helped to determine the compatibility of growth, the peculiarities of the formation of the root system, which gave grounds to recommend a new kind of this culture for more distribution.

Interestingly, on soils with a smectite composition of mollusc fraction, phenomena of salinization and soda formation are more often observed.

In Iraq, 2 field experiments were conducted to determine the size of the crystals and the standards for applying gypsum to melioration of heavy saline soils and sunflower crops [14]. The best crystals were the minimum size (less than $2 \mathrm{~mm}$ ) and ore with gypsum content more than $15 \%$. In this variant, the thickness of the soil crust decreased from 6 to $2.5 \mathrm{~mm}$, and the density of the structure - from 1.58 to $1.42 \mathrm{~g} / \mathrm{cm}^{3}$.

Increased parameters of salinity and meadowness were reduced (by 31.7-40.5 \%) due to the growth of halophytes, which affected electrical conductivity, $\mathrm{pH}$, capacity of cation exchange, especially in relation to sodium [15]. In a similar experiment in Turkey it was managed to reduce the meadowness of the secondary saline soil by the introduction of PVA and sulfuric acid.

Abu Dhabi (Emirates) has for the first time implemented a broad program for evaluating and mapping deserted land using remote sensing, geo-information and ground-based observations [16]. As a result, a ground-information system was created and it was found that $23 \%$ of the territory is highly degraded soils that need to be improved. In addition, there are a lot of sand dunes, where there is a high probability of dust storms, or soils that are lined with dense rocks at a small depth.

The same project is being carried out in Tunis with the participation of local experts, FAO experts and UNEP financial support. The Land Degradation Assessment in Dryland (LADA) project has two main objectives: to develop methods for spatial assessment of desertification degradation, and to propose typical methods for the reconstruction of desert zones and the formation of sustainable ecosystems.

In Iran, different models of evaluation, classification and mapping of deserted soils, including the FAO and UNEP models, have been tested. As a result, two Iranian models were developed. In addition, in Iran the GLASOD model was successfully adapted to evaluate the degradation of soil fertility. It is important to note that contours of soils with different fertility were determined using photometric satellite information. In accordance with the European nitrates charter, monitoring surveillance is gradually being developed. 
Thus, in Turkey measurements of nitrates in rivers, irrigated waters and adjacent soils at 919 stations are carried out.

Recently, new approaches to modeling and forecasting, based on so-called fuzzy sets and fuzzy logic, which are not often used even in developed Western European countries, extend. There are used the original methods of removing pollutants from irrigation wastewater, for example, using nanoparticles (less than $0.1 \mu \mathrm{m}$, which have a high absorption capacity), or with $\mathrm{Al}_{2} \mathrm{O}_{3}$.

Likewise it is for overcoming the allelopathic toxins, or reducing the mobility of pollutants. In Iran, the use of TDR (time domain reflectometer) for automated determination of soil moisture on irrigated lands is becoming widespread. In Turkey and Iran there are attempts to study the heterogeneity of the field by geostatistical methods and apply precision farming.

Increasingly wider is remote sensing гыштп, not only for addressing traditional issues (mapping and diagnostics of erosion), but also for assessing salinization of soils. Small aircraft (Quickbirdimages) with high resolution and speed of diagnosis are used. An unconditional interest has works on the study of the influence of elevated temperatures on the course of soil processes, especially related to infiltration, in particular pollutants that are not carried out in Ukraine.

In Arabic countries, there are popular studies on phytotherapy, with various ways of using it. In particular, rhizophiltration (the ability of plant roots to concentrate heavy metals from contaminated emissions), phyto-stabilization (the ability of root plants to fix contaminants in the soil), phytodegradation (the ability of plants and microorganisms to destroy organic pollutants), phytoimmobilization (reducing the availability of soluble contaminants), phytololization (preventing the transfer of pollutants into the atmosphere), phytoextraction (accumulation of pollutants in the overlying mass of plants). Moreover, the fundamental scientific works of this direction are well known here [17]. Phytotherapy is fairly considered a promising method of soil and environmental purification.

Oil producing countries in the Arab world have traditional topics related to bioremediation of oilcontaminated soils. These studies have been launched since the last century together with oil developments [18]. Today, especially in Iran, research on hydrocarbons that fall into the soil of different genesis and granulometric composition during oil production is distributed.

It turned out that in the countries of the Near and Middle East, as well as in European countries, popular topics are related to the assessment of soil quality. Here, the works of European researchers on these issues [19-21] and FAO recommendations [22] are often cited. Among indicators, there are used the useful soil volume, physical clay and sludge content, ground water level, carbonate and bicarbonate content, electrical conductivity, cation exchange capacity and the amount of exchangeable sodium. It is characteristically absence among the indicators of humus content and nutrients.

Thus, in the countries of North Africa, the Near and the Middle East, various studies are conducted on soil science, which are important for agriculture in arid conditions. There is a high culture of pastures, adapted to the needs of sheep breeding and breeding camels. The issue of improving pasture and seed production for them is at the center of attention. There are observed carefully the standard load of sheep per unit area of pasture, because the pressure of hoofing of these animals on the soil can be compared to the pressure of heavy tractors. These measures continue to prolong the effective use of pasture and reduce the cost of their support and recovery. If in Ukraine, the plans for the re-naturalization of unproductive and degraded land become real, then the organization of pasturing, for example, in Jordan, Morocco or Iran, would be very useful.

No less attractive is a culture of water management, which in countries with sharply arid climate is the object of high technology and even art [2]. Here they can appreciate every drop of water, keep it, minimizing losses. Often there are various closed containers and reservoirs for collecting and storing moisture of precipitation. You can pay attention to the ability to use artesian wells, moist surface runoff, to collect water that is accumulated in decreases (children of Bedouin always have containers behind them to collect such water).

By the way, the more children in the family of the Bedouin, so he is more prosperous because he can feed more sheep. And in Israel even the peaks of hills are cover with hydrophobic polymers and thus get 
the opportunity to accumulate water in decrements and grow vegetables there without watering. In these countries, people learned to desalinate sea water and create its reserves.

Arab countries are interested in applying polymers for light granulometric structure and anti-erosion, as observed in most western European countries of the United States.

In Turkey together with American researchers conduct experiments on effective use of atmospheric moisture on sandy soils. To do this at a depth of $40 \mathrm{~cm}$ there are created special screens that can accumulate water and minimize its evaporation. Striking results have been obtained - the corn yield on silo compared to control has increased by 5 times.

In Arabic countries, there are popular studies of various types of degradation (especially related to wind erosion and desertification), irrigation measures (in particular, with the help of mineral waters), research on melioration of saline soils (by means of drainage), saline soils (gypsum), cultivation of stone soils with the use of special tools, develop ways to contain soils that reduce pollution. A lot of works are devoted to the creation of artificial soils for regulated climates. Unfortunately, these original research of Arab scientists are completely unknown in our country.

In the Arabian countries, there are many studies of desertification problems, researchers survey new underground water sources for irrigation, methods of their use, focus on water quality determination and the application of various methods for its improvement. There is study of gypsum-bearing soil, common in the Arab countries. The lack of criteria used to address the issue of attracting them to irrigation is noted. Actual are in-depth studies of their genesis, fertility, designing measures to protect against degradation. Gypsum soils are not always reasonably involved in irrigation (even with the content of gypsum more than $80 \%$ and its superficial occurrence), higher irrigation norms are used for their development, using deep drafts, obviously less effective than non-lean, methods of basic cultivation.

The plow also clearly increases the danger of wind erosion. Mineral fertilizers used on these soils are ineffective, because the nutrition elements contained in them are fixed in the soil by gypsum. Methods of studying these soils are needed to be improved, especially water-physical, physical-chemical properties, organic matter. The American system used to classify them does not fully take into account the large variety of gypsum soils, differences in content and depth of gypsum layout, and the dimension of its crystals.

It turns out that the scientific topics related to the search for the best substrates for artificial climatic structures in the UAE and Kuwait have been developing for many years and are being introduced into production on a large scale. For this purpose, quite large, expensive buildings were built and reserves of desalinated sea water were created. It should be noted that even stadiums with controlled climates are planned to be built here, which guarantees the successful holding of the World Cup in 2022 in Qatar in the summer.

The growth of the economic welfare of some Arab states makes it possible to implement ambitious plans. Moreover, these countries are already practically ready for the period when the oil reserves are exhausted. They successfully master innovation technologies, new production, services, and prestigious tourism. In the most developed Arab countries, the hopelessness of the raw material economy and the need for adaptation of states, in particular land use and food production, to the new conditions have long been understood.

Therefore, it is no coincidence that countries such as Egypt and Turkey (with a population of 70-80 million people and unfavorable climatic conditions) not only provide their own food needs, but also substantial exports. In addition, businessmen from Kuwait, Qatar, OAU are actively investing in leading Western campaigns, becoming not only their co-owners, but also at the same time mastering advanced technologies. Many works of Arab researchers are performed with the participation of scientists from the United States, Japan, European countries.

It is worth paying attention to how the research are organized. They are usually carried out by the efforts of all or several Arab countries. Despite the different political orientations of the Arab countries, military conflicts and the destructive role of IDIL, scientific contacts between the countries are not torn. 
For example, the Arab Center for the Studies of Arid Zones and Drylands (ACSAD) continues to work, which, through military confrontation with Syria, has been transferred to Jordan.

It brought together researchers from Arab countries who studied or trained in the best universities of the West. The Center conducts a variety of studies, collects information and develops recommendations. The center uses researchers from Western countries as consultants [23]. There is also a center (ICARDA) specializing in selection work, mainly in the field of grain crops. And even in Iraq, which is involved in military actions, research and educational institutions for soil science and agriculture continue their activities, as evidenced by numerous reports by Iraqi researchers at the last congress of soil scientists.

Land use in most Arab countries is based on effective and constantly updated soil information and the development of methods for reducing climate dependence. The success of this experience is evidenced by the markets of Damascus, Istanbul or Cairo. The variety and quantity of food products on them is significant, they are not worse than the Parisian markets. Therefore, we should be skeptical about the optimistic statements of our politicians about the great prospects for exporting agricultural products to Arab countries. It will be difficult to do this because it people used to American grains, Brazilian sugar, Italian olive oil, and it will be difficult to change anything in the mentality of the Arabs, because it requires exceptionally high quality and inexpensive products that the Ukrainian exporter cannot offer. Equally important is the fact that Ukraine is extremely poorly known in the countries. So, almost 1,000 publications (total 5 volumes at more than 4000 p.) were presented at the last congress of soil scientists, the vast majority was from Turkey and Iran. In these articles there was any (!) reference to Ukrainian researchers.

\section{Conclusions}

The climatic conditions of agriculture in the countries of North Africa, the Near and the Middle East are not simple, besides complicated by modern negative soil processes of desertification, deflation, salinity. Despite this, the experience of active adaptation to adverse conditions has been developed in the countries. It should be interesting to Ukrainian scientists and practitioners, especially on pastures, water resources, the development and implementation of the latest methods of phytotherapy, the use of artificial soil, etc. In countries, especially in Turkey and Iran, there are numerous scientific and educational institutions that carry out a variety of research at the present level. The scientific and industrial experience of countries with a dry climate deserves attention and research in Ukraine.

\section{Bibliography}

1. H. Avci. A New Approach on Combating Desertification and Erosion in Turkey. 8th International Soil Science Congress on "Land Degradation and Challenges in Sustainable Soil Management"/H.A. Avci. - Izmir. Turkey. 2012. - V. 1 - P.3-5.

2. Hosseini S.M. Construction and Development of Green Landscape in Arid Regions of Iran. 8th International Soil Science Congress on "Land Degradation and Challenges in Sustainable Soil Management"/ S.M. Hosseini, S. Rahimi. - Izmir. Turkey. 2012. - V. 1- P.43-46.

3. Abdesselam S. Land Use Change and Soil and Water Degradation in South Hodna, Algeria. 8th International Soil Science Congress on "Land Degradation and Challenges in Sustainable Soil Management"/ S. Abdesselam, A. Halitim - Izmir. Turkey. 2012. - V. 1. - P. 432 - 435.

4. In-Situ Wind Erosion Measurement and Soil Loss Estimation: Karapınar Case study. 8th International Soil Science Congress on "Land Degradation and Challenges in Sustainable Soil Management"/ M. Başaran, A.U. Özcan, O. Uzun, G. Erpul, S. Deviren, F. Youssef. - Izmir. Turkey. 2012. - V. 1. — P. 6.

5. Evaluation of Land Degradation Using Spatial Modeling Approach A Case Study in the Wadi El Hallouf Watershed (Médenine-Tunisia). 8th International Soil Science Congress on "Land Degradation and Challenges in Sustainable Soil Management"/ M.B. Zaied, M. Ouessar, M. Kirkby, B. Irvine. - Izmir. Turkey. 2012. - V. 1. - P. 356-362.

6. Effect of Adding Different Sizes and Levels of Gypsum Stone in Some Physical Soil Properties and in the Crop of Sunflower 8th International Soil Science Congress on "Land Degradation and Challenges in Sustainable Soil Management"/ E. Babaeian, A. Bahrami, H.A. Bahrami, F. Sharifi. - Izmir. Turkey. 2012. - V. 1. - P. 258-263. 
7. Matinfar H.R. Survey on Satellite Data Potentials in Dust monitoring. 8th International Soil Science Congress on "Land Degradation and Challenges in Sustainable Soil Management"/ H.R Matinfar, M.A. Soorghali. - Izmir. Turkey. 2012. - V. 1. - P. 378-381.

8. Amiri I. Climatic Controls of Dust Emissions in Western Iran. An Examination Based on Dust Storm Frequency from 1975 to 2005. 8th International Soil Science Congress on "Land Degradation and Challenges in Sustainable Soil Management"/ I. Amiri, S.M. Hosseini. - Izmir. Turkey. 2012. - V. 1. P. 252-257.

9. Bahrami A. Deforestation Effects on Some Soil Properties in North of Iran. 8th International Soil Science Congress on "Land Degradation and Challenges in Sustainable Soil Management"/ A. Bahrami, F. Aghamir, F. Bagheri, M.R. Atashi, M.S. Shahrestani. - Izmir. Turkey. 2012. - V. 1. - P.7.

10. Ortaş İ. Significance of Carbon in the Development of Soil Structure. 8th International Soil Science Congress on "Land Degradation and Challenges in Sustainable Soil Management"/ İ. Ortaş, R. Lal, S. Kapur. - Izmir. Turkey. 2012. - V. 1. - P. 192.

11. Nael M. Evaluation of Soil Degradation in Different Rangeland Management Systems Via a Soil Quality Approach in Central Iran. 8th International Soil Science Congress on "Land Degradation and Challenges in Sustainable Soil Management"/ M. Nael, H. Khademi, J. Mohammadi. - Izmir. Turkey. 2012. - V. 1. - P. 8.

12. Jafaria I. Effect of Grazing Intensity on Soil Physical Properties (Case Study: Miankale Protected Area in North of Iran). 8th International Soil Science Congress on "Land Degradation and Challenges in Sustainable Soil Management"/ I. Jafaria, H.N. Gharmakher. - Izmir. Turkey. 2012. - V. 1. - P. 1920.

13. Khodaverdiloo H. Soil Physical Quality as Influenced by Man - Made Land Uses and Deforestation. 8th International Soil Science Congress on "Land Degradation and Challenges in Sustainable Soil Management"/ H. Khodaverdiloo, K. Ghodrat, H. Sadaghianii, S. Rezapour, H. Karimi. - Izmir. Turkey. 2012. - V. 1. - P. 47-52.

14. Al-Hasser Y.H. Effect of Adding Different Sizes and Levels of Gypsum Stone in Some Physical Soil Properties and In the Crop of Sunflower. 8th International Soil Science Congress on "Land Degradation and Challenges in Sustainable Soil Management"/ Y.H. Al-Hasser. - Izmir. Turkey. 2012. - V. 1. - P. 264-268.

15. Darbandi S. Reduction of soil salinity and sodicity by Aellenia glauca, Salsola soda and Halocnemum strobilaceum8th International Soil Science Congress on "Land Degradation and Challenges in Sustainable Soil Management" / S. Darbandi, F. Farahvash, S. Amiraslani. - Izmir. Turkey. 2012. - V. 1. - P. 303-307.

16. Abdelfattah M.A. Assessment and Mapping of Degraded Lands in the Desert Environment of Abu Dhabi Using Geoinformation Technologies. 8th International Soil Science Congress on "Land Degradation and Challenges in Sustainable Soil Management"/ M.A. Abdelfattah. - Izmir. Turkey. 2012. - V. 1. - P. 81-87.

17. Kaptan H. Phytoremediation Mechanisims and Applications. 8th International Soil Science Congress on "Land Degradation and Challenges in Sustainable Soil Management"/ H. Kaptan. - Izmir. Turkey. 2012. - V. 1. - P. 495-497.

18. Soil Petroleum Hydrocarbon Contamination Cleanup by Bioremediation. 8th International Soil Science Congress on "Land Degradation and Challenges in Sustainable Soil Management"/ S.S. Alikhani, M. Shorafa, A. Asgharzadeh, S. Masiha. - Izmir. Turkey. 2012. V. 1. - P. 16-18.

19. Standardization of soil quality attributes/ D.N. Karlen, M.J. Mausbach, J.W. Doran et al.//Agriculture, Ecosystems \& Environment.1997. - № 88. - P. 161-168.

20. Nortcliff S. Soil quality: A concept, definition and framework for evaluation/ S. Nortcliff// Soil Science Society of America J. - 2002. - № 61. - P. 4-10.

21. Rossiter D.G. A theoretical framework for land evaluation (with discussion). - Geoderma, 1996. - № 72. - P. 165-202.

22. A framework for land evaluation. 1976, Soils Bulletin. № 32. FAO: Rome.

23. Shamsutdynov Z.Sh. Arydnoe zemledelye $v$ arabskykh stranakh/Z.Sh. Shamsutdynov, R.M. Udachyn, V.V. Medvedev//Vestn. s.-kh. nauky. - 1990. - \# 6. - S. 157-160. 